ESTRANHAS ENTRANH DE ANTROPOLOG E ÚTE 


\section{ESTRANHAS ENTRANHAS: DE ANTROPOLOGIAS, E ÚTEROS}

\section{DANIELA TONELLI MANICA}




\title{
ESTRANHAS ENTRANHAS: DE ANTROPOLOGIAS, E ÚTEROS
}

\section{Resumo}

Esse artigo busca explorar as sinergias e fabulações possíveis ao pensar e discutir, de uma perspectiva antropológica, as temáticas que se desdobram a partir da concepção (simbólica e concreta, material-semiótica) dos "úteros". Ao tomar o útero como foco, emergem questões (histórica e teoricamente problemáticas) como a do feminino, seus deslocamentos e (im)possíveis estabilizações; a dos corpos e seus agenciamentos que implicam classificações, regulações e (des)controles; e conexões esboçáveis entre as expressões estéticas, estruturas e arranjos socioantropológicos e as temáticas de gênero/corpo/sexualidade e reprodução. O texto perpassa abordagens que levam em conta o "corpo" no pensamento grego e na biomedicina, no pensamento ameríndio e melanesiano, com enfoque privilegiado sobre temáticas do útero, sangue (menstrual) e gênero. Propõe, por fim, o reconhecimento da importância política dessas temáticas na antropologia.

Palavras-chave: antropologia, corpo, gênero, útero e sangue menstrual

\section{STRANGE ENTRAILS: ANTHROPOLOGIES, AND UTERUS}

\begin{abstract}
This paper aims to explore the possible synergies and confabulations in thinking and discussing, from an anthropological perspective, the themes that unfold from the (symbolic and concrete, material-semiotic) conception of the "uterus". By taking the uterus as a focus, (historically and theoretically problematic) issues emerge such as the feminine, its displacements and (im)possible stabilizations; the bodies and their agencies that imply classifications, regulations and (un)manageability; and the sketched connections between aesthetic expressions, structures and socio-anthropological arrangements, and the thematic of gender/body/ sexuality and reproduction. The text presents approaches that take into account the "body" in Greek thought and bio-medicine, in Amerindian and Melanesian thought, with a privileged focus on the themes of the uterus, (menstrual) blood and gender. It proposes, finally, the recognition of the political importance of these themes in anthropology.
\end{abstract}

Keywords: anthropology, body, gender, uterus and menstrual blood 


\section{ENTRAÑAS EXTRAÑAS: DE ANTROPOLOGÍAS, Y ÚTEROS}

\section{Resumen}

Este artículo busca explorar las sinergias y las fabulaciones posibles al pensar y discutir, desde una perspectiva antropológica, las temáticas que se desdoblan a partir de la concepción (simbólica y concreta, material-semiótica) de los "úteros". Al tomar el útero como foco, emergen cuestiones (histórica y teóricamente problemáticas) como la del femenino, sus desplazamientos e (im) posibles estabilizaciones; la de los cuerpos y sus agencias que implican clasificaciones, regulaciones y (des)controles; y conexiones que se puedan esbozar entre las expresiones estéticas, estructuras y arreglos socioantropológicos y las temáticas de género/cuerpo/ sexualidad y reproducción. El texto pasa por enfoques que tienen en cuenta el "cuerpo" en el pensamiento griego y en la biomedicina, en el pensamiento amerindio y melanesio, con enfoque privilegiado sobre temáticas del útero, sangre (menstrual) y género. Propone, por fin, el reconocimiento de la importancia política de esas temáticas en la antropología.

Palabras clave: antropología, cuerpo, género, útero y sangre menstrual

Daniela Tonelli Manica

dtmanica@unicamp.br 
O sangue, como os pensamentos, circula. Nisso reside seu poder. Se são armazenados em excesso, estancam, apodrecem ou transbordam. Se se deixam correr, escorrem e secam. Os pensamentos, incluindo as emoções, são estados do sangue. (Belaunde 2005: 38). ${ }^{1}$

Eventos-chave (..) são em grande parte inacessíveis para a ciência. Eles ocorrem na escuridão do útero humano antes mesmo de a maioria das mulheres saber que está grávida. (Regalado 2017). ${ }^{2}$

\section{INTRODUÇÃO}

Esse texto busca explorar as sinergias e fabulações possíveis de duas iniciativas de pensar e discutir, de uma perspectiva antropológica, as temáticas que se desdobram a partir da concepção (simbólica e concreta, material-semiótica) dos "úteros". Parto de uma releitura do evento "Estranhas entranhas: as múltiplas ontologias do "útero", organizado por mim, Daniela Manica (PPGSA/IFCS/UFRJ) e por Luisa Elvira Belaunde (PPGAS/MN/UFRJ) realizado no IFCS/UFRJ em novembro de 2016. ${ }^{3} \mathrm{E}$ também da disciplina Antropologia do(s) Útero(s), ministrada no PPGAS/UnB pelas professoras Soraya Fleischer e Rosamaria Carneiro em 2017 (Fleischer e Carneiro 2017), cujos textos de trabalhos finais, revistos e reformulados, compõem os artigos deste dossiê.

Talvez não à toa, esses dois pontos que aqui (re)tomo como de partida aconteceram quase que simultaneamente à exposição "O útero do mundo", no
Museu de Arte Moderna de São Paulo. ${ }^{4}$ De curadoria de Verônica Stigger, a exposição ocorrida entre setembro e dezembro de 2016 foi inspirada em uma revisita à obra de Clarice Lispector. ${ }^{5}$ Além de "o útero do mundo", outras expressões de sua obra conferiram o fio condutor que organizava o encadeamento das obras selecionadas. ${ }^{6}$

Do universo das belas artes e da literatura, a proposta de curadoria produz um movimento também esboçado no evento e no referido curso, que inclui, entre outros afetos e intuições, provocar sentidos que emergem da concepção do útero - como "matriz", instável, indomável, errante e mutante - e/ou do corpo e do humano em suas transformações, metamorfoses e em comunicação com o "outro" e com o "fora". Ao tomar o útero como foco, emergem questões (histórica e teoricamente problemáticas) como a do feminino, seus deslocamentos e (im)possíveis estabilizações, a dos corpos e seus agenciamentos que implicam classificações, regulações, (des)controles, e conexões esboçáveis entre as expressões estéticas, estruturas e arranjos socioantropológicos e as temáticas de gênero/ corpo/sexualidade e reprodução.

Partindo das inspirações trazidas por esses afetos e no movimento de transbordá-los para um espaço teórico-analítico que se baseia em incursões etnográficas e antropológicas, neste artigo procuro então abordar a vida e suas grafias, a origem e a ontogênese, de uma perspectiva que ensaia formas possíveis (e ético-politicamente aceitáveis) de repensar corporalidades, para 
além dos limites colocados pelas divisões disciplinares da Antropologia e da Biologia.

\section{ESTRANHAS ENTRANHAS}

Mulheres são estranhas, sangram pelas entranhas. (Pichação no bairro do Tietê, SP, 2002)

"Estranhas entranhas" foi a forma de nomear um evento que pretendeu fazer convergir pesquisas antropológicas sobre as temáticas do útero/corpo e da maternidade/reprodução, em amplos e diversos contextos sociais e históricos. $^{7}$ Foi inspirada em uma frase que encontrei pichada em um muro próximo à rodoviária do Tietê, em São Paulo, quando chegava para fazer minha pesquisa de campo do mestrado, em um congresso médico de ginecologia e obstetrícia que acontecia na cidade. Uma das primeiras anotações no meu caderno de campo, e que sintetizava uma questão ainda candente para pensar corpo, gênero, biomedicina e reprodução.

Recupero a expressão porque ela traduz duas dimensões ainda relevantes: em primeiro lugar, o estranhamento em relação a mulheres e seus corpos ("mulheres são estranhas") - referência que sugere (embora não determine) um grau de alteridade do autor ("homem”?) em relação ao referente genérico ("mulheres"). Questão clássica aos estudos de gênero que Simone de Beauvoir (1949) sintetizou na ideia de um "segundo sexo". Segundo, a do útero e da menstruação - o sangramento das "entranhas" do corpo - abjeto, interdito, circunscrito. De seus mistérios, po- deres, e que inclui as diversas maneiras possíveis, de acordo com o contexto socioantropológico, de manejar e entender os processos corporais, a vida, os corpos e a reprodução. ${ }^{8}$

Mas antes de mais nada: que é uma mulher? "Tota mulier in utero: é uma matriz”, diz alguém. Entretanto, falando de certas mulheres, os conhecedores declaram: "Não são mulheres", embora tenham um útero como as outras. [...] Todo ser humano do sexo feminino não é, portanto, necessariamente, mulher; cumpre-lhe participar dessa realidade misteriosa e ameaçada que é a feminilidade. (Beauvoir 2000[1949]:7).

Tentar responder à pergunta "o que é uma mulher?" levou Beauvoir, logo na primeira página do primeiro volume d'O Segundo Sexo, a evocar o útero como foco sobre o qual se tensiona a constituição da diferença. Seu livro apresenta, na sequência, um longo apanhado do conhecimento disponível na época acerca da diferença sexual e da reprodução biológica em diferentes espécies de seres vivos, plantas e animais (o que situa o "útero" em uma perspectiva biológica e reprodutiva). No entanto, a obra caminha no sentido de uma constatação da complexidade que envolve o processo social de construção dessa diferença na sociedade ocidental.

O que se segue à célebre frase que inicia o segundo volume ("ninguém nasce mulher, torna-se mulher") é uma descrição minuciosa de como esse processo se produz como "experiência vivida", tendo como referência principal a sociedade francesa (e europeia) da 
época. Corpo, menarca, sexualidade e maternidade são situados nesse contexto, de uma perspectiva inspirada pela psicanálise, e sensível à diferença na valoração das experiências de corpos divergentes, explicitando algumas das ambiguidades possíveis.

[... A vida da menina sempre lhe apareceu como determinada por essa impalpável essência que a ausência do pênis não conseguia dar uma figura positiva: é esta que se descobre no fluxo de sangue que lhe escorre entre as coxas. Se já assumiu sua condição é com alegria que ela acolhe o acontecimento... "Agora, és uma mulher". Se sempre a recusou, o veredito sangrento a fulmina; o mais das vezes ela hesita: a mácula menstrual inclina-a para a repugnância e o medo: "Eis então o que significam essas palavras: ser mulher!" [...] Em uma sociedade sexualmente igualitária, ela só encararia a menstruação como sua maneira particular de atingir a vida adulta; o corpo humano conhece nos homens e nas mulheres muitas outras servidões mais repugnantes [...]. As regras inspiram horror à adolescente porque a precipitam numa categoria inferior e mutilada. [...] Conservaria o orgulho de seu corpo sangrento se não perdesse seu orgulho de ser humano. (Beauvoir 1986[1949]:56).

A menstruação então marca uma confirmação inicial do "tornar-se mulher", mas dessa passagem decorre uma certa "ausência" de humanidade, ou uma humanidade secundária, "inferior". A perspectiva crítica feminista que se anuncia em Beauvoir contribui para problematizar as relações entre corpo e gênero, pela percepção das ciladas (e limites) inerentes à existência dessa entidade "mulher". Discussão que se desenvolve politicamente no feminismo de segunda onda e nos estudos de gênero durante a segunda metade do século XX. A diferença entendida como sexual, e situada na fisiologia reprodutiva, é simultaneamente interrogada como uma explicação possível para a "universalidade da subordinação feminina" (Ortner 1979), e refutada como tal (Strathern 1991).

O corpo se configura, nesse contexto, uma importante (e problemática) arena na definição das identidades (de gênero, entre outras, como raça, por exemplo), na sustentação de estruturas de desigualdade (através de uma ênfase na constituição de diferenças, corporificadas), compondo os diversos agenciamentos que envolvem o biopoder (Foucault 2003 [1976]). Mas a ideia de uma diferença sexual, ancorada fundamentalmente nos corpos femininos e masculinos, cujas naturezas seriam distintas, é considerada por alguns autores como um caso específico da sociedade ocidental, situável historicamente.

Ao analisar os discursos e representações sobre corpo e a diferença sexual "dos gregos a Freud", Thomas Laqueur (2001 [1992]) propõe a tese de que, até o renascimento, o que prevalecia era um modelo "do sexo único", no qual o "homem" era a medida de todas as coisas, a definição de corpo humano e de perfeição. Nesse modelo, o que hoje entendemos como órgãos sexuais femininos (vagina, ovários, útero) apareciam com uma representação invertida (e "entranhada", interioriza- 
da) dos "órgãos sexuais masculinos", uma versão inferior e menos perfeita do corpo "humano". As primeiras representações anatômicas das dissecações sugerem a leitura do útero como o equivalente interno do escroto. Laqueur explora a homologia entre a ideia de bolsa (escrotal) e a da matriz (útero), capazes de guardar e produzir, mas cuja potência generativa é dimensionada em relação ao referente masculino.

É interessante notar como, nos desenhos e gravuras que o autor analisa, as dimensões dos órgãos são aproximadas, e as representações do útero grávido parecem de fato, aos "nossos" olhos, subdimensionadas:
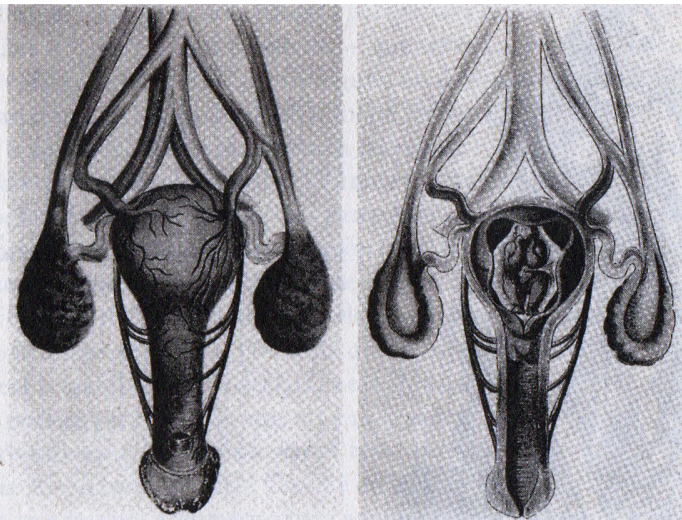

Figs. 30-31. À esquerda, os órgâos reprodutivos femininos semelhantes ao pênis. Em Kunstbuche (1575), de Georg Bartisch. A direita, a frente do útero é cortada para mostrar seu conteúdo.

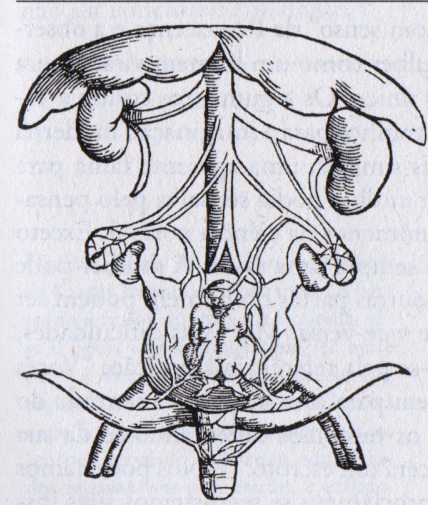

Fig. 32. Orgãos reprodutivos femininos. Em Anathomia (1541), de Walther Ryff. Nesta ilustração e na próxima, notem que a vagina e o útero seriam mais semelhantes ao pênis e ao escroto se os chifres fossem eliminados e a vagina desenhada em proporção correta, isto é, se fossem mais exatas.

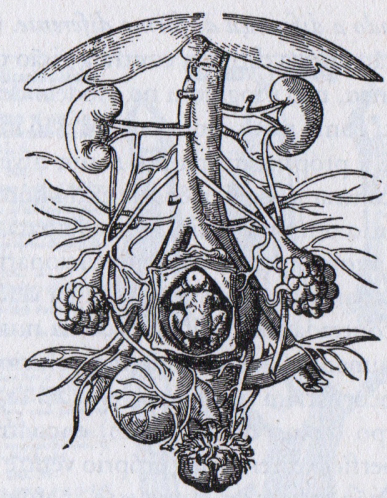

Fig. 33. Orgãos reprodutivos femininos, em Habammenbuch (1583), de Jacob Rueff, publicado em inglês com o título de The Expert Midwife (1637), muito popular e amplamente plagiado. Notem que o ureter esquerdo foi cortado e a bexiga empurrada para a direita a fim de podermos olhar pela janela do ventre e ver o feto.

Figura 1: Reprodução de página do livro "Inventando o sexo", no qual Thomas Laqueur reproduz algumas ilustrações do século XVI feitas sobre o "útero", "vagina” e demais órgãos (Laqueur 1991: 113). 
Seu argumento segue no sentido de mostrar como, a partir do século XVIII, a diferença entre homens e mulheres (o "gênero") passa a residir também nos corpos e a Biologia, como ciência, se torna a narrativa mais legítima para desenhar essa natureza distinta: "O ventre, que era uma espécie de falo negativo, passou a ser o útero - um órgão cujas fibras, nervos e vascularização ofereciam uma explicação e uma justificativa naturalista para a condição da mulher" (Laqueur 2001:192). E então útero, ovários, vagina, nesse primeiro momento do desenvolvimento de uma biomedicina mais fisicalista e organicista passam a ser nomeados como tais, retratados, escrutinados. Num momento posterior da história da biomedicina, também os hormônios sexuais, os genes e a atividade cerebral compõem esse cenário de diferença "incorporada" (Oudshoorn 1999; Nucci 2010).

No caso brasileiro, trabalhos importantes (Carrara 1996; Rohden 2001, entre outros) indicam como as relações entre corpo, gênero e sexualidade estão articuladas aos projetos de constituição nacional, e a um controle moral sobre as ações de homens e mulheres no que diz respeito à sua sexualidade, e seus efeitos reprodutivos. Esses autores procuram resgatar os discursos e práticas médico-científicas que se tornaram, ao longo dos séculos XVIII-XX, hegemônicas na defesa dessas diferenças sendo situadas na biologia dos corpos, como efeitos da "natureza" e, portanto, supostamente incontestáveis e imutáveis.

No entanto, o sentido de estabilidade que se almejaria atribuir a um fato classificado como "biológico" ou "natural" não aparece como um fato incontestável. Ao analisar as teses de ginecologia e obstetrícia defendidas na Faculdade de Medicina do Rio de Janeiro no século XIX, Fabíola Rohden demonstra o quanto essa suposta "natureza" se mostra, na verdade, como sendo "instável e perigosa":

[...] Os médicos estão o tempo todo dizendo que existe de fato uma diferença natural entre homens e mulheres. Mas, isso não quer dizer que ela seja estática ou dada a priori. Ela parece estar sujeita a intervenções externas. É natural mas não definitiva. $\mathrm{Na}$ verdade, se ela fosse definitiva, dada por variáveis puramente biológicas e imutáveis, as ameaças a sua integridade não chamariam tanto a atenção dos médicos. (Rohden 2001:203).

A natureza aparece caracterizada como algo passível de descontrole e subversão, e isso reflete preocupações da ordem do social, simbólico, moral e seus efeitos nas relações de gênero:

A intensidade com que os discursos médicos se propuseram a falar das diferenças calcadas na natureza mostra o quanto elas pareciam imprescindíveis naquele contexto. Era com base naquilo que descreviam como natural que os médicos criavam prescrições relativas às funções sociais de homens e mulheres. Era porque viam no corpo feminino apenas a manifestação da capacidade reprodutiva que desestimulavam ou mesmo condenavam a educação e o trabalho feminino fora de casa. [...] Para a medicina da época, a natureza já havia esta- 
belecido a divisão e a ordem que a sociedade deveria reproduzir e da qual não se podia, ou não se queria, escapar. (Rohden 2001: 207-208).

"Ciência da diferença" foi a definição dada pela autora, no título do livro, às áreas da ginecologia e obstetrícia, cujo desenvolvimento não foi simétrico, na época, ao da andrologia. Seus principais objetivos envolviam, como sua análise bem demonstra, caracterizar a fisiologia reprodutiva feminina de modo a contribuir com argumentos socialmente legítimos, uma vez que eram chancelados como científicos, para tentar restringir as possibilidades de ação e circulação dos corpos femininos (brancos, evidentemente) à esfera do doméstico e da maternidade. $\mathrm{O}$ processo de socialização "adequado" seria, então, uma forma (secundária) de assegurar que essa natureza não fosse "desvirtuada" pela educação ou pelo trabalho.

Essa "domesticação" incidiu, sobretudo, sobre a sexualidade e seus efeitos sociais e reprodutivos nos corpos femininos. A histeria e a ninfomania, embora sejam descritas incorporando aos aspectos "fisiológicos" questões "psicossociais", resguardam a referência nesse corpo "diferente" como sendo a origem dos transtornos e desordens. No caso da "histeria", apesar da origem etimológica do nome remeter ao útero [do grego hystera, e latim uterus], as teses oscilavam entre localizar a sede da desordem como sendo no útero ou no cérebro (Rohden 2001: 139), ou ainda como algo mais da ordem comportamental e psicológica, uma "perturbação moral" (: 141), com efeitos deletérios para a sociedade. Os tratamentos, da mesma forma, variavam entre a prescrição do casamento e da submissão ao universo doméstico e maternal, as cirurgias castradoras (ovarotomia, clitoridectomia, histerectomia e ablação endometrial) e tratamentos psiquiátricos de reclusão (Rohden 2001: 144-149).

Talvez não seja correto situar o "Brasil", que é amplo e diverso demais para configurar uma categoria homogênea, como parte da "sociedade ocidental" herdeira direta do Iluminismo e da Ciência como empreendimentos históricos. No entanto, trabalhos focados na formação do Estado em grandes centros urbanos brasileiros consolidam uma perspectiva de continuidade entre os processos de colonização no Brasil, as matrizes europeias e as formas e arranjos simbólicos e sociais encontrados em cidades brasileiras. Nesse sentido, podemos pensar os processos de constituição das ciências (e, especificamente, da medicina) no Brasil como também desdobramentos do empreendimento colonial, e que atualizam a noção do "corpo feminino" como diferente e específico em sua natureza.

Uma análise complexa e interessante das relações entre corpo e gênero em Portugal pode ser vista no trabalho de Teresa Joaquim (1997). A autora parte da maneira como o pensamento grego sobre a natureza feminina influenciou a percepção sobre a mulher como um ser diferente, inferior e marcado pela negatividade de sua natureza. Citando Platão:

Nas mulheres [...] o que se chama matriz ou útero é um animal que 
vive nelas com o desejo de procriar. Quando ele fica muito tempo estéril depois do período da puberdade, ele tem dificuldade em suportar isso, indigna-se, erra por todo o corpo, bloqueia os canais do sopro, impede a respiração, causa um grande incómodo e origina doenças de todas espécie, até que, o desejo e o amor unindo dois sexos, eles possam colher um fruto, como numa árvore, e semear na matriz, como num sulco, animais invisíveis pela sua pequenez e ainda informes, em seguida, diferenciando as suas partes, alimentá-los no interior, fazê-los crescer, depois, dando-os à luz, acabar a geração dos animais. Tal é a origem das mulheres e de todo o sexo feminino. (Timeu, 90b-92b, ed 1969: 467-8 apud Joaquim 1997:71). ${ }^{10}$

O útero, esse animal errante e perturbador que só se acalma quando gesta um feto, seria então a síntese da "origem das mulheres e do sexo feminino". Joaquim passa também pelas formas como a medicina medieval e a tradição cristã contribuíram para a atribuição de uma idealização do feminino a partir dos seus atributos reprodutivos e não erotizados, através das figurações da pecadora e da reprodutora, de Eva à Maria. Segundo ela, em provocadora sugestão: "Talvez que nesse mito da Virgem e Mãe se diga quase tudo o que o imaginário masculino desejou e produziu sobre o corpo das mulheres" (Joaquim 1997:131). Em seu trabalho, Joaquim se interroga "o que pode um corpo" quando constituído a partir desse lugar de diferença.

Num modelo culturalmente construído em que as mulheres foram pensadas como solo, natureza, matéria - lugar inicial de imaginário e de afectos, de conhecimento e de ignorância - nesse domínio desde sempre reservado às mulheres, num modelo em que a dominação masculina passa pelo princípio de ordem, da forma que o masculino inscreve na matéria, pergunto-me e deixo-me como hipótese - como um trabalho futuro - se hoje, quando nos interrogamos, que corpos fomos? em que corpo nos tornamos?, se o domínio reservado masculino não passa por, ou não subsiste ainda num imaginário em que o acesso à abstracção permanece ainda interdito às mulheres. Mas a abstracção talvez não seja a do "corpo abstracto" mas antes a duma lógica em que experiências diversificadas, e o corpo e a palavra, a denegação e o reconhecimento, sejam possíveis, em que "pensar seja criar possíveis". (Joaquim 1997:451).

Dimensão que ela explora mais profundamente em outro trabalho, interrogando-se sobre como lidar com o logocentrismo filosófico sendo mulher: "[...] talvez por isso, essa mistura de ser e não-ser provoque ainda a busca de um lugar - a impossibilidade de ser filósofa [...] -, de uma nova casa, de uma morada que permita habitar a Terra de modo humano. Morada que não existe sem ser, sem pensamento, sem vida." (Joaquim 2006:83).

\section{CORPO E PERSPECTIVISMO}

Considerando a multiplicidade de povos africanos, indígenas, entre outros, que compõem e compuseram esse arranjo contingente chamado Brasil, há 
uma diversidade muito maior do que "nos" traz a matriz europeia para as maneiras de conceber corpos, gênero e sexualidade. Em um trabalho clássico, Seeger, Da Matta e Viveiros de Castro já apontavam a centralidade da corporalidade para as sociedades indígenas brasileiras, temática que contribuiu para a reflexão antropológica sobre a noção de pessoa:

[...] sugerimos que a noção de pessoa e uma consideração do lugar do corpo humano na visão que as sociedades indígenas fazem de si mesmas são caminhos básicos para uma compreensão adequada da organização social e cosmologia dessas sociedades (Seeger, Da Matta e Viveiros de Castro 1979:3).

Contudo, conceber a centralidade do corpo para a estruturação e cosmologia de sociedades ameríndias não significa, obviamente, encará-lo da forma como o pensamento ocidental, herdeiro das tradições greco-romanas e do iluminismo, o faz. Pensar o corpo nesse sentido implica também desfazer pressupostos e romper com dicotomias, como as que foram problematizadas pelas perspectivas pós-estruturalistas e pós-modernistas, a saber: natureza versus cultura, corpo versus mente, indivíduo versus sociedade, entre outras.

Conforme propõe Cecilia Mc Callum (2001) ao introduzir sua monografia sobre os Kaxinawá, e alinhada a essa forma de pensar o corpo (Mc Callum 1998), gênero é produzido não como um processo de construção social sobre o dado biológico (o corpo), mas como uma "capacidade corporificada de produção e reprodução":
No caso Kaxinawá, o trabalho implicado em produzir a si mesmos como "pessoas reais" (Huni Kuin) - sua autodenominação - simultaneamente produz gênero como uma capacidade encorporada [embodied] para a produção e a reprodução. Gênero pode ser entendido como uma condição epistemológica para a ação social, que se acumula na carne e nos ossos dos seres humanos como agência masculina ou feminina. Uma vez que eu tenha demonstrado detalhadamente como isso se dá, eu irei examinar como gênero constitui a própria socialidade, quando a agência humana é exercida dentro de um arranjo interdependente de relações sociais. Eles geram a socialidade através de uma série de transformações produtivas e reprodutivas no ciclo econômico que conecta predação, trabalho, apropriação, distribuição, troca, circulação e consumo. (Mc Callum 2001:5). ${ }^{11}$

De uma perspectiva parecida, Marylin Strathern (2014 [1980]) defende que a oposição entre natureza e cultura, que fundamenta um dos grandes divisores do pensamento ocidental, não pode ser reduzida a uma dicotomia, compondo, na verdade uma complexa e variável matriz de contrastes. Dessa forma, a existência dessas noções e seus múltiplos sentidos não pode ser considerada universal. ${ }^{12}$

Assim, é possível reler a visão científica (ocidental, biológica) sobre a diferença sexual como uma maneira, dentre outras, de conceber pessoa, gênero e corporalidade. E não necessariamente a ideia de um "corpo feminino", ou de seus aspectos "reprodutivos" funcio- 
nar como uma determinação definitiva. Gênero não parece ser algo que se "tem" ou que se "é", mas, no sentido melhor explorado por Judith Butler (1993), a ação corporificada, mais os sentidos que são a ela atribuídos.

Strathern argumenta que, considerando o caso do povo melanesiano Hagen, não se encontra entre eles uma relação totalmente equivalente à nossa oposição entre cultura e natureza (que envolve hierarquia, dominação, colonização e transcendência). A forma como os Hagen concebem mbo e romi talvez tenha a ver, em contrastes específicos, com alguns dos sentidos que "atribuímos" a cultura e natureza, social e não social, selvagem e doméstico. Mas a relação entre esses pares de oposição é distinta, não configura uma dicotomia, e não envolve controle e poder.

Eles utilizam uma noção de um domínio para além eles mesmos (romi) para significar as características do vínculo humano (mbo), mas essa própria distinção é inata, sujeita a descoberta, não a reformulação. Assim, a humanidade é demarcada em relação ao não humano, mas não procura controlá-lo. $O$ controle vem de dentro, é um atributo autodefinidor do mundo social. [...] Não existe cultura, no sentido dos trabalhos cumulativos do homem, e não existe uma natureza a ser amansada e tornada produtiva. E ideias como essas não podem ser um referente da imagética de gênero. Os Hagen de fato utilizam expressões de gênero para falar sobre os interesses sociais em oposição aos interesses pessoais e sobre o cultivado como distinto do selvagem. Mas esses domínios não são colocados em relação sistemática; a metáfora mediadora, do domínio da cultura sobre a natureza, não está lá. Pelo contrário, na medida em que o gênero é utilizado de maneira diferenciante, dialética, a distinção entre masculino e feminino constantemente cria a noção de humanidade como um "fundo de semelhança comum" (Wagner, 1975: 118-119). Nem o masculino nem o feminino poderiam representar a "humanidade" em contraposição à "natureza" porque a distinção entre eles é utilizada para avaliar as áreas nas quais a ação humana é criativa e individuante. Assim toda a questão do controle parece de fato estar circunscrita no interior da noção das coisas mbo. As representações de dominação e influência entre os sexos tratam precisamente de formas de interação humana; não tratam também do projeto da humanidade em relação a um mundo menos do que humano. (Strathern 1991:74-75).

A provocação que o trabalho de Strathern traz para as tentativas teóricas (acadêmicas) de contribuir para pensar reivindicações feministas (como a "subordinação universal das mulheres") envolve, portanto, deslocar a questão das relações entre corpo/sexo e gênero, entre natureza e cultura. E situar as nossas próprias categorias no universo de relações específico ao pensamento "euroamericano" sobre corpo e diferença. As implicações dessa crítica obrigam não somente a repensar as relações entre corpo e gênero (e, portanto, a categoria de "mulher" como algo universal e ancorado no corpo), como os pressupostos coloniais que 
fundamentam as relações pelas quais esse termo é tornado possível (no caso, a dominação da cultura pela natureza).

Uma leitura otimista dessa crítica poderia nos levar a imaginar, talvez, noções possíveis (e desejáveis) de humanidade - que possam incorporar a diferença para além da figura estanque e limitada de um "sujeito moderno ocidental". As relações entre corpo e diferença, humanidade/cultura e animalidade/natureza são, também, problematizadas pelos esforços teóricos que compreendem pensar o "perspectivismo ameríndio" (Lima 1996; Viveiros de Castro 1996). $\mathrm{Na}$ proposição mais conhecida:

Uma perspectiva não é uma representação porque as representações são propriedades do espírito, mas 0 ponto de vista está no corpo. Ser capaz de ocupar o ponto de vista é sem dúvida uma potência da alma, e os não-humanos são sujeitos na medida em que têm (ou são) um espírito; mas a diferença entre os pontos de vista (e um ponto de vista não é senão diferença) não está na alma, pois esta, formalmente idêntica através das espécies, só enxerga a mesma coisa em toda parte - a diferença é dada pela especificidade dos corpos. (Viveiros de Castro 1996:128).

Uma só cultura (ou “alma”) e muitas, múltiplas naturezas, o inverso do pensamento "ocidental" sobre natureza e cultura. O que varia é a natureza, e a humanidade/cultura é uma alma comum a todos os seres viventes. A diferença está nos corpos. Mas, apesar de ser o foco de onde se define o ponto de vista, esse "corpo" não deve ser tomado a partir dos nossos pressupos- tos do que um corpo "é" (sinônimo de biológico, natural, característico de uma espécie "animal"). E sim, da sua capacidade de ser afetado, e dos efeitos dessas afecções nas ações e relações que se estabelecem.

O que estou chamando de "corpo", portanto, não é sinônimo de fisiologia distintiva ou de morfologia fixa; é um conjunto de afecções ou modos de ser que constituem um habitus. Entre a subjetividade formal das almas e a materialidade substancial dos organismos, há um plano intermediário que é o corpo como feixe de afecções e capacidades, e que é a origem das perspectivas. (Viveiros de Castro 1996:128).

Ao recuperar essa passagem, e em uma releitura dos temas do xamanismo e do perspectivismo ameríndio que leva em conta gênero como uma questão, Luisa Elvira Belaunde propõe situar mais concretamente essa corporeidade, sugerindo que, no contexto amazônico, a operatória dessas perspectivas pode ser atribuída ao sangue como substância:

Os aspectos da hematologia amazonense [...] revelam o que poderia ser chamado uma teoria transcultural "réptil" do sangue articulada com a noção de "troca de pele/corpo", chave para a cosmologia e o xamanismo perspectivista amazonense. Se, como Viveiros de Castro (1996, p. 128) argumenta, o corpo é o local das perspectivas, então, sugiro que o sangue é um operador de perspectivas. Na Amazônia, o sangue é uma substância psicoativa, provavelmente a mais forte. Ele leva pensamento e força e incorpora os espíritos e o conhecimento de uma pessoa, trazendo de volta 
à memória o conhecimento de si e dos parentes, mantendo a vida. $\mathrm{O}$ sangue tanto une quanto divide os seres humanos em homens e mulheres. Em primeiro lugar, porque o sangue transporta conhecimento corporificado, atribuindo gênero à pessoa; em segundo, porque $\mathrm{O}$ sangramento é explicitamente uma posição feminina, embora ela não seja ocupada apenas por mulheres. (Belaunde 2006:232).

Segundo Belaunde para os airo-pai o sangue opera, como "perspectiva", a gramática (e a pragmática) corporificada do gênero:

Partindo da etnografia airo-pai para lançar as bases de uma hematologia amazonense, defendo que o sangue constitui o principal veículo para a igualdade de gêneros assim como para a diferença. O sangue é uma relação que tanto une quanto divide os seres humanos em homens e mulheres. De fato, uma variedade de etnografias mostra que o sangue é concebido como uma relação porque ele circula pelo corpo, pondo todas as suas partes em comunicação e enchendo-as de pensamento e força para a ação intencional. (Belaunde 2006:210).

Os sentidos de materialidade, fungibilidade e trânsito/fluxo do sangue (Carsten 2013) são importantes para seu rendimento operatório. Seu aparecimento recorrente com os sangramentos menstruais, e, portanto, sua potencial (e perigosa) circulação no mundo compartilhado, contribui para consolidar sua centralidade nas dinâmicas vitais em questão. A despeito da reclusão, dietas e da evitação do contato direto com o sangue menstrual, o reconhecimento de seu poder é decorrente do ato periódico de menstruar, sangrar, e do que esse ato põe em circulação: poder e perigo, mas sobretudo gênero, conhecimento e pensamento.

O sangramento é uma capacidade feminina de conhecimento, implicando consequências sociais das mais significativas, e pode ser visto como um poder feminino, ao invés de um índice da subordinação feminina. Ao mesmo tempo, o conhecimento do sangramento não é conferido unicamente às mulheres, já que os homens também nascem do sangue vertido por elas e podem também sangrar e causar sangramento a si mesmos e a outros. (Belaunde 2006: 226).

Como fabular então perspectivas antropológicas que considerem essas possibilidades de conceber o "corpo" como um intermediário entre "alma" e "organismo" (Viveiros de Castro 1996), como um "corpo que sabe" (Mc Callum 1998), ou do sangue como "pensamento, conhecimento e memória", operador de perspectivas, e da corporificação do gênero (Belaunde 2006)? Como articular esses deslocamentos num movimento "reverso" (Wagner 2010 [1975]) que contribua para repensar as relações entre corpo e gênero, e a própria Antropologia?

Deslocar o polo da multiplicidade para a natureza, e para os corpos, é um movimento nesse sentido. Que Annemarie Mol (2002) bem formulou na ideia de "corpo múltiplo" - aquele que é "mais que um, mas menos que muitos" -, inspirada na discussão sobre conexões parciais de Strathern (1991), baseada por sua vez no clássico "Ma- 
nifesto Ciborgue" de Donna Haraway (1991 [1985]). Trata-se, portanto, de um passo para trás em relação à epistemologia, e um adiante no sentido de considerar (políticas) ontológicas:

O movimento, então, é de um distanciamento da epistemologia. A epistemologia está preocupada com referências: ela pergunta se as representações da realidade são acuradas. Mas o que se torna importante se nos atentamos à forma como se "fazem existir" os objetos na prática é algo bem diferente. (Mol 2002:vii). ${ }^{13}$

Como então, reinscrever a dimensão da corporalidade sem partir do pressuposto de um corpo biológico "padrão" e "único", atentando às ciladas das essencializações? Como pensar gênero, o útero e o "feminino" (como diferença corporificada) depois de todas essas críticas?

A partir de questões como essas e de uma pesquisa etnográfica sobre hormônios e a menstruação em Salvador, Emilia Sanabria (2017) desenvolve o conceito de "corpos plásticos" [plastic bodies] para tratar dos corpos em sua materialidade e também nos sentidos contingentes que eles adquirem, em fluxo com o mundo, as substâncias e narrativas que os perpassam. Certamente não é à toa que "útero" e o "sangue menstrual" tenham sido formas privilegiadas que a autora evoca para construir essa análise de pensar sobre corpos, e suas fronteiras, na contemporaneidade.

\section{MÚLTIPLAS ONTOLOGIAS E "ÚTE- ROS"}

O desdobramento mais previsível de um interesse antropológico pelo "útero" como tema envolve congregar trabalhos sobre gênero e maternidade. Tanto no evento "Estranhas entranhas", quanto na disciplina "Antropologia do(s) útero(s)" essas temáticas protagonizaram as discussões, ainda que de maneiras diversas.

Decidir colocar foco no "útero", sempre "tensionado quando no singular", e como uma "ideia-forma provisória e polissêmica" (Fleischer e Carneiro 2017) não tem somente a ver com as nossas trajetórias pessoais e profissionais, embora tenha também. É uma aposta na importância - enunciada há tempos, desde os primeiros trabalhos presentes no início deste texto por exemplo (dentre muitos outros) -, de repensar o humano de uma perspectiva mais abrangente, que inclua (problematizando) os corpos e as questões de desigualdades, diferenças, hierarquias, trazidas pelos movimentos feministas, LGBTQIs, negros, indígenas, ecológicos, de pessoas com deficiência etc. No sentido, também, de tentar fazer a reflexão antropológica contribuir para a construção de um mundo mais justo, plural, e menos desigual. Talvez algo que tenha a ver com o impacto e a sensação de contraste e violência de gênero que causa (me causa, até hoje) a imagem a seguir, e seus efeitos para a política da contingência-Brasil contemporânea. 


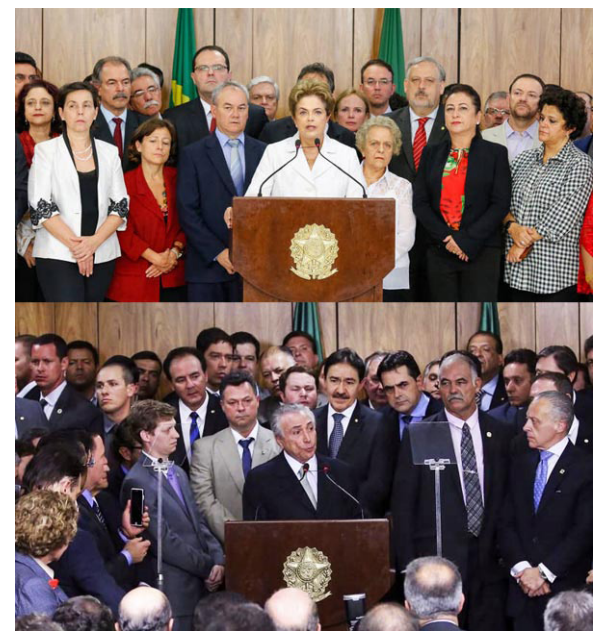

Figura 2: Fotografias, em contraste, do pronunciamento de Dilma Rousseff no Palácio do Planalto às vésperas de seu afastamento (11/05/2016) e do discurso de posse de Michel Temer como presidente interino após admissão do processo do impeachment (12/05/2016).

Como coloca Haraway, importa imensamente quais escolhas e recortes fazemos com nossas pesquisas, e que escolhas podemos/queremos fazer. Importa "quais pensamentos pensam pensamentos, quais histórias contam histórias" (Haraway 2016:39). Importa falar sobre corpos, sobre úteros, sobre maternidades. Se levamos adiante uma leitura do perspectivismo informada pela crítica de gênero, falar disso é falar do humano, no sentido em que ele se torna "toda uma outra coisa" (Viveiros de Castro 2015:54). Ou seja, numa "outra" versão, não antropocêntrica, nem racista, machista, misógina, homo/lesbo/trans/fóbica, capacitista e todas as demais limitações que cabem às ações conservadoras com as quais temos sido confrontadas. Se for o caso de manter o "humano" como referen- te (como relação, utopia, como devir) é preciso refundá-lo a partir do que as perspectivas dos corpos divergentes, a quem a humanidade foi historicamente negada, tem a acrescentar. ${ }^{14}$

Dentre os tensionamentos possíveis dessa discussão está a reivindicação por uma libertação da teleologia reprodutiva dos corpos com útero. Desmontar a interpretação desses corpos como máquinas de produzir bebês (Martin 2006 [1987]) e abrir para novas e outras possibilidades de ser e de agir (Manica 2017). Exorcizar o fantasma, num totalitarismo fascista sempre iminente, da redução da nossa existência a essa condição de "reprodutoras" - pesadelo-(im?) possível recuperado recentemente pela releitura de Margaret Atwood (2017 [1985]). Mas sem desvalorizar o desejo e as potências da procriação e das diversas, múltiplas e prazerosas formas de maternagem. Desvincular, enfim, a relação determinante entre corpo e gênero, e abrir as formas possíveis de vida para múltiplas expressões dos afetos e das corporalidades.

O movimento aqui proposto é algo que fica entre um re-encantamento do corpo, objetificado pela tecnociência, um resgate do seu valor generativo, da potência criativa que é/pode ser o "útero"; e a insistência na atribuição de mais valor às experiências, múltiplas $\mathrm{e}$ complexas, da maternagem e do cultivo da vida, que incluem o doméstico e a nutrição. Mas que seja um movimento que não aprisione esses corpos na obrigatoriedade compulsória da gestação e da maternidade, que não atualize versões normativas de um essencialismo biológico sufocante, e que, por- 
tanto, reconheça "mulheres" e demais minorias em sua plena "humanidade" - o que envolve o direito de decidir se, quando e como gerar, parir e amamentar. Envolve o direito básico de existir.

Sobretudo, no Brasil, é preciso assegurar às mulheres negras, a quem tem sido sistematicamente negado, ao longo da nossa história colonialista e escravagista, o direito de gerar e de ver crescer e florescer seus filhos. Aos povos indígenas e quilombolas o direito à terra, à floresta, à água, ao ar. São muitas e múltiplas as formas de violência contra a vida, e corpos marcados pela diferença (menos "humanos") são o alvo preferencial. Os artigos que se seguem nesse dossiê trazem muitas dessas questões em um arranjo caleidoscópico muito bem-vindo para complexificar e abrir os sentidos possíveis do(s) "útero(s)" para repensar essas questões socioantropológicas clássicas, e ainda atuais.

Uma das noções centrais para o desenho do evento "estranhas entranhas" foi a de "mãe/dona do corpo". ${ }^{15}$ Presente no contexto afroindígena brasileiro. A noção compõe configurações variáveis em cada análise, mas que convergem em aspectos interessantes: abertura, fechamento e multiplicidade dos corpos; a errância, inquietude e movimento desse "ser" interno, a dona/mãe do corpo; a importância do resguardo e do devido cuidado com os corpos e atenção a momentos vitais especiais (como gestação, parto e puerpério). Falar sobre útero e mãe do corpo evoca discussões sobre parentesco, casa, nutrição e força. Sobre vida, terra e crescimento. A mãe do corpo, quan- do desestabilizada, vaga pelo corpo provocando perturbações e doenças. Ressoa, nesse sentido, a ideia do útero errante e perturbado, presente no pensamento grego.

Desordem, descontrole, perturbação. A histeria como impermanência, loucura, paixão é evocada, e positivada, por Stigger (2017) como um lugar possível para a arte. Em que medida poderemos positivar as antropologias dos úteros, também, em sua capacidade de produzir uma ruptura indisciplinada em relação à nossa tradição antropo-andro-logo-centrada (Despret e Stengers 2011)? É o que temos aqui e pela frente, uma agenda linda e urgente, de ação antropológica.

\section{NOTAS}

${ }^{1}$ No original: "La sangre, como los pensamientos, circulan. En esto reside su poder. Si son almacenados en exceso, se estancan, se pudren o se rebalsan. Si se dejan correr; se escurren y se secan. Los pensamientos, incluyendo las emociones, son estados de la sangre". Tradução livre.

${ }^{2}$ No original: "Key events [...] are largely inaccessible to science: they occur in the darkness of the human uterus even before most women know they're pregnant". Tradução livre.

${ }^{3}$ Programação disponível em: https://leicufrj.wordpress.com/eventos/

As apresentações e debates do evento podem ser vistas no canal: $\quad$ https://www.youtube.com/ atch? $\mathrm{v}=\mathrm{tC} 4 \mathrm{a} 323$ YoWk\&list $=$ PLhylNy-GsAURqx158ihiVJr5D5nkkuEC0

${ }^{4}$ http://mam.org.br/exposicao/o-utero-do-mundo/ 
5 "Entro lentamente na escritura, assim como já entrei na pintura. É um emaranhado de cipós, sílabas, madressilvas, cores e palavras - limiar de entrada de ancestral caverna que é o útero do mundo e dele vou nascer." Lispector, 1998 [1973].

${ }^{6} \mathrm{~A}$ exposição foi organizada nas sessões intituladas, respectivamente, Grito ancestral, Montagem humana e Vida primária.

${ }^{7}$ Agradeço ao Pedro Peixoto Ferreira, a quem devemos, Luisa e eu, os créditos dessa formulação.

${ }^{8}$ A relação entre sangue menstrual e estranhamento abre, também, uma reflexão pioneira sobre menstruação no Brasil, de uma perspectiva feminista, no artigo de Cecilia Sardenberg (1994).

${ }^{9}$ Não faz parte do escopo do trabalho um recorte intersseccional, uma vez que o material das próprias teses parece desconsiderar a pluralidade de situações e experiências socioeconômicas e raciais das mulheres, $\mathrm{O}$ que complexificaria toda essa discussão sobre o doméstico, a maternidade e o trabalho. No entanto, a autora aponta como, também para a questão racial, a problemática do corpo e da biologia está colocada no sentido de reificar a diferença como inata, e reforçar desigualdades sociais.

${ }^{10} \mathrm{O}$ trecho que precede imediatamente essa seleção fala também da forma como "homens" aparecem retratados por Platão: "[...] Eis porque nos machos os órgãos genitais são naturalmente insubmissos e autoritários, como animais surdos à voz da razão e, dominados por apetites furiosos, querem comandar tudo. Nas mulheres [...]" (idem, ibidem).

${ }^{11}$ No original: "In Cashinahua case, the work that goes into producing themselves as 'Real Persons' (Huni Kuin) - their self-denomination - simultaneously produces gender as an embodied capacity for production and reproduction. Gender may be understood as an epistemological condition for social action, one that accumulates in the flesh and bones of proper human beings as either male or female agency. Once I have shown how this is done in some detail, I go on to examine how gender constitutes sociality itself when human agency is exercised within an interdependent set of social relationships. They generate sociality through a series of productive and reproductive transformations in the economic cycle linking predation, work, appropriation, distribution, exchange, circulation and consumption". Tradução livre.

${ }^{12} \mathrm{~A}$ fertilidade feminina não é mais nem menos inata do que o poder que os homens revelam na interação com fantasmas e espíritos. (Strathern 2014: 67).

${ }^{13}$ No original: The move, then, is away from epistemology. Epistemology is concerned with reference: it asks whether representations of reality are accurate. But what becomes important if we attend to the way objects are enacted in practices is quite different. (Mol 2002: vii). Tradução livre.

Segui aqui algumas sugestões de tradução do verbo "enact" por "fazer existir".

${ }^{14}$ Esse comentário é um desdobramento das trocas e conversas com Pedro Ferreira, que se desenvolveram, entre outras situações, no seminário temático "Antropologia e Antropocentrismos: debates, desafios e perspectivas", que coordenamos juntos na VI ReACT, Reunião de Antropologia da Ciência e da Tecnologia, realizada em maio de 2017 na Universidade de São Paulo (Manica e Ferreira 2017).

${ }^{15}$ Sistematizar as reflexões e convergências em etnografias nas quais o conceito da mãe/dona do corpo aparece ainda é um trabalho a se fazer. Para além das apresentações e textos das pesquisadoras Julia 
Sauma (2016), Yara Alves (2016), Márcia Nóbrega (2016) e Luisa Elvira Belaunde (2016), ver também McCallum et. al. (2015), Victora (1999) e Fleischer (2011).

\section{VIDEO-WEB-BIBLIOGRAFIA}

Alves, Yara. 2016. Dona do corpo, maternidade e casa: Tramas femininas das famílias de Pinheiro- MG. Estranhas Entranhas: as múltiplas ontologias do "útero". Disponível em: https://youtu.be/DxAEZaRvsi4

Atwood, Margaret. 2017 [1985]. O conto da aia. Rio de Janeiro: Rocco.

Beauvoir, Simone de. 2000 [1949]. O segundo sexo. Vol.1. Rio de Janeiro: Nova Fronteira.

1986 [1949]. O segundo sexo.

Vol.2. Rio de Janeiro: Nova Fronteira.

Belaunde, Luisa Elvira. 2005. El recuerdo de Luna: género, sangre y memoria entre los pueblos amazónicos. Lima: Fondo Editorial de la Facultad de Ciencias Sociales UNMSM.

2006. A força dos pensamentos, o fedor do sangue. Hematologia e gênero na Amazônia. Revista de Antropologia da USP. v.49 n.1: 205-243.

2016. Dona do corpo e concepção da saúde feminina a longo prazo entre os povos indígenas do nordeste. Estranhas entranbas: as múltiplas ontologias do "útero”. Disponível em: https://youtu.be/ PxkXcw2dVt0

Butler, Judith. 1993. Bodies that matter: on the discursive limits of sex. New York and London: Routledge.

Carrara, Sergio. 1996. Tributo a Vênus: a luta contra a sífilis no Brasil da passagem do século aos anos 40. Rio de Janeiro: Fiocruz.

Carsten, Janet. 2013. Introduction: blood will out. Journal of the Royal Anthropological Institute (N.S.) S1-S23.
Despret, Vinciane e Stengers, Isabelle. 2011. Les faisenses d'bistoires. Que font les femmes à la pensée? Paris: La découverte. Fleischer, Soraya. Parteiras, Buchudas e Aperreios. Uma etnografia do cuidado obstétrico não oficial na cidade de Melgaço, Pará. Santa Cruz do Sul, Edunisc, 2011.

Fleischer, Soraya e Carneiro, Rosamaria. 2017. Programa de curso: Antropologia do(s) útero(s). Disponível em: http:// www.dan.unb.br/images/pdf/ppgas/programas-disciplinas/2017/1-2017Antropologia da Saude Soraya Rosamaria.pdf

Foucault, Michel. 2003 [1976]. História da Sexualidade 1: a vontade de saber. Rio de Janeiro: Graal.

Haraway, Donna. 1991[1985]. A cyborg manifesto: science, technology, and socialist-feminism in the late twentieth century. In: Simians, cyborgs and women. The reinvention of nature. London: Free Association Books Ltd., pp.149-181.

.2016. Staying with the trouble. Making kin in the chthulucene. Durham and London: Duke University Press.

Joaquim, Teresa. 1997. Menina e moça: a construção social da feminilidade. Lisboa: Fim de século Edições. 2006. A (im)possibilidade de ser filósofa. In: As causas das mulheres: a comunidade infigurável. Lisboa: Livros Horizonte. pp. 68-86.

Laqueur, Thomas. 2001 [1992]. Inventando o sexo: corpo e gênero dos gregos a Freud. Rio de Janeiro: Relume Dumará.

Lima, Tania Stolze. 1996. O dois e seu múltiplo: reflexões sobre o perspectivismo em uma cosmologia tupi. Mana 2(2): 21-47. Lispector, Clarice. 1998 [1973]. Água Viva. Rio de Janeiro: Rocco.

Manica, Daniela Tonelli. 2017. As CeSaM: células do sangue menstrual. In: Revista 
DR. Ed.4. Dossiê: Reprodução e Magia. Disponível em: http://www.revistadr.com. $\mathrm{br} / \mathrm{posts} / \mathrm{as}$-cesam-celulas-do-sangue-menstrual

Manica, Daniela Tonelli e Ferreira, Pedro Peixoto. 2017. Seminário Temático 6: Antropologia e Antropocentrismo: debates, dilemas e perspectivas. Anais da VI ReACT. Vol. 3. N.3. p.1 Disponível em: http://ocs.ige.unicamp.br/ojs/react/article/view/2622/2323

Martin, Emily. 2006 [1987]. A mulher no corpo: uma análise cultural da reprodução. Rio de Janeiro: Garamond.

Mc Callum, Cecilia. 1998. O corpo que sabe da epistemologia kaxinawá para uma antropologia médica das terras baixas sul-americanas. In: Alves, PC., e Rabelo, MC. orgs. Antropologia da saúde: traçando identidade e explorando fronteiras. Rio de Janeiro: Fiocruz e Relume Dumará, pp. 215245.

2001. Gender and sociality in Amazonia: how real people are made. Oxford and New York: Berg.

Mc Callum, Cecilia; Macedo, Ulla; Menezes, Greice e Belaunde, Luisa. 2015. A "dona do corpo" e o "resguardo quebrado": a etiologia tupinambá numa perspectiva etnográfica. In: Mc Callum, Cecília e Rohden, Fabíola. Corpo e saúde na mira da Antropologia: ontologias, práticas, traduções. Salvador: EdUFBA e ABA Publicações. pp. 45-65

Mol, Annemarie. 2002. The body multiple: ontology in medical practice. Durham and London: Duke University Press.

Nóbrega, Márcia. 2016. A mãe em movimento: tempo, espaço e corpos em uma ilha no Rio São Francisco. Estranhas entranhas: as múltiplas ontologias do "útero". Disponível em: https://youtu.be/mvL0-ckKr54
Nucci, Marina. 2010. Hormônios pré-natais e a ideia de sexo cerebral: uma análise das pesquisas biomédicas sobre gênero e sexualidade. Dissertação de Mestrado, Programa de Pós-Graduação em Saúde Coletiva, Universidade do Estado do Rio de Janeiro. Ortner, Sherry. 1979. Está a mulher para o homem assim como a natureza para a cultura? In: Rosaldo, Michelle e Lamphere, Louise. A mulher, a cultura e a sociedade. Rio de Janeiro: Paz e Terra, pp. 95-120.

Oudshoorn, Nelly. 1999. Beyond the Natural Body: an archeology of sex hormones. London: Routledge.

Regalado, Antonio. Artificial Human Embryos Are Coming, and No One Knows How to Handle Them. MIT Technology Review, Sept. 19, 2017. Disponível em: https://www.technologyreview. $\mathrm{com} / \mathrm{s} / 608173 /$ artificial-human-embryosare-coming-and-no-one-knows-how-tohandle-them/

Rohden, Fabiola. 2001. Uma ciência da diferença: sexo e gênero na medicina da mulher. Rio de Janeiro: Editora Fiocruz.

Sanabria, Emilia. 2017. Plastic Bodies: sex hormones and menstrual suppression in Brazil. Durham and London: Duke University Press.

Sardenberg, Cecilia. 1994. De sangrias, tabus e poderes: a menstruação numa perspectiva socioantropológica. Revista Estudos Feministas 2 (2), p. 314-344

Sauma, Julia. 2016. Todas as mães: corpos, lugares e parentes quilombolas na Amazônia. Estranhas entranhas: as múltiplas ontologias do "útero". Disponível em: https:// youtu.be/tC4a323YoWk

Seeger, Anthony; Da Matta, Roberto; Viveiros de Castro, Eduardo. 1979. A construção da pessoa nas sociedades indígenas brasileiras. In: Boletim do Museu Nacional. Número 32. Rio de Janeiro. 
Stigger, Veronica. 2017. O útero do mundo. Catálogo do Museu de Arte Moderna de São Paulo. p. 7-48 Disponível em: http://mam. org.br/wp-content/uploads/2016/10/outerodomundo.pdf

Strathern, Marylin. 1991. Partial Connections. Savage, Md.: Rowman and Littlefield.

2014 [1980]. Sem natureza, sem cultura: o caso Hagen. In: O efeito etnográfico e outros ensaios. São Paulo: Cosac Naify. pp23-75.

Victora, Ceres G. A ‘mãe do corpo’ dentro do corpo da mãe. 1999. Corpus. Porto Alegre: Cadernos do NUPACS.

Viveiros de Castro, Eduardo. 1996. Os pronomes cosmológicos e o perspectivismo ameríndio. Mana 2(2):115-144.

2015. Perspectivismo. In: Metafísicas canibais: elementos para uma antropologia pós-estrutural. São Paulo: Cosac Naify e N-1 Edições. pp. 33-54

Wagner, Roy. 2010. A invenção da cultura. São Paulo: Cosac Naify. 